\title{
ESTUDIOS
}

\section{SALUD PÚBLICA Y POLÍTICA AGRARIA LIBERAL EN ESPAÑA. LA INSPECCIÓN DE SANIDAD DEL CAMPO (1910-1918)"}

\author{
Esteban Rodríguez-Ocaña
}

Dpto. A.P. e Historia de la Ciencia, Universidad de Granada

\section{RESUMEN}

Abordo el significado en la historia de la Salud pública española de la Inspección de Sanidad del Campo (1910-1918) partiendo de fuentes escasamente conocidas producto de una búsqueda sistemática en las revistas médicas de la época y en el Boletín de Agricultura técnica y económica, órgano de la Dirección general de Agricultura. La Inspección dependió del Ministerio de Fomento, al igual que la higiene veterinaria, y su objetivo era proporcionar bases higiénicas para un plan de infraestructuras agrarias, lo que se tradujo en una ingente tarea de vigilancia epidemiológica sobre anquilostomiasis, paludismo, aguas y alimentación. En este sentido resulta un perfecto epítome de la tradición informativa liberal, así como un complemento de la política hidráulica impulsada por Rafael Gasset.

PALABRAS CLAVE: Salud rural. Vigilancia epidemiológica. Historia de la Salud Pública. España. Siglo XX.

\section{PUBLIC HEALTH AND AGRARIAN LIBERAL POLITICS IN SPAIN: THE RU-} RAL HEALTH BUREAU (1910-1918)

\section{ABSTRACT}

This paper reviews the meaning of the Rural Health Bureau (1910-1918) for the history of Spanish public health, thanks to a wealth of previously unknown sources found through a system-

* Versiones preliminares de este trabajo se presentaron en sendas reuniones sobre «History and geography of health: the territory and its social construction as a key determinant of health» $y$ «Health and the rural in Europe (1860-1970): Organisations, Practices and Campaigns», ambas celebradas en octubre de 2008, en Ginebra y Valencia respectivamente. 
atic search through medical journals of the time and the Bulletin of the national department of Agriculture. The Bureau was dependent of the Ministry of Development, in the same way as the competences on animal health. It aimed to provide a public health rationale for a plan of agrarian infrastructures, a goal resolved into a huge task of surveillance on hookworm disease, malaria, water supplies and diet. Thus it becomes a perfect paradigm of the Spanish Liberal tradition of promoting information instead than actual changes into society, as well as a needed complement to the hydraulic policy sponsored by Rafael Gasset.

KEY WORDS: Rural health. Health surveillance. History of Public Health. Spain. 20th Century.

INTRODUCCIÓN. HISTORIOGRAFÍA Y FUENTES PARA EL ESTUDIO DE LA INSPECCIÓN DE SANIDAD DEL CAMPO

El objeto de este trabajo es analizar la aportación de la efímera (19101918) Inspección de Sanidad del Campo (ISC) a la salud pública en España. Dicha Inspección presenta dos aspectos sumamente originales; por una parte, se creó dentro de las dependencias de Agricultura (Ministerio de Fomento) y no ligada a Sanidad (Ministerio de la Gobernación), mientras que, por otra, se configuró como una institución de vigilancia epidemiológica, con objetivos notoriamente amplios, pues incluían la observación, notificación y estudio de determinadas enfermedades junto con las condiciones físicas y sociales que las condicionaban. Desde la perspectiva profesional, suponía la quiebra de la adjudicación monopolística de competencias en el ramo y debilitaba la fuerza de la naciente especialización sanitaria. Su justificación entroncaba con un concepto de salud ambiental debilitado en esos momentos por el ascenso de la bacteriología e inmunología.

Hasta la fecha, la historiografía española solo ha prestado atención a este segundo aspecto; en forma concisa diríamos que no se ha encontrado nada bueno en dicha iniciativa, que se conceptua como un error y un fracaso. Todo remonta al mismo texto del RD que la cerró, obra de Francisco Cambó en un gobierno Maura, donde se hablaba de «un organismo cuya escasa eficiencia es notoria, no por incompetencia del ilustrado personal que lo integra, sino por defectos de organización», de los cuales el principal era su separación de la rama principal de la administración sanitaria ${ }^{1}$. Insistiendo en esta idea, la Historia de la Sanidad de Rico-Avello no para en barras y acusa a la ISC de ejercer la «competencia desleal» a la Sanidad oficial ${ }^{2}$. Desde tal perspectiva,

$1 \quad$ RD 23 octubre 1918. Gaceta del 26, p. 282.

2 Rico-Avello, C. (1969), Historia de la sanidad española, 1900-1925, Madrid, E. Giménez, pp. 55-57 y 177-179. 
para él la creación de la ISC fue «decisión realmente vejatoria», que significó un «escarnio», y su actividad fue «desconcertante», generó interferencias o resultó «francamente agobiante». Personalidades destacadas de la década de 1920, como Gustavo Pittaluga y Marcelino Pascua, se refirieron a los errores factuales y metodológicos de la ISC en lo tocante al paludismo. En particular gozan de autoridad las críticas de Pascua, en tanto que nuestro más destacado experto en estadística sanitaria, cuando señalaba los errores metodológicos que invalidaban como fuente los Avances de los inventarios de Paludismo y Aguas Potables (Madrid, Ministerio de Fomento. Dirección General de Agricultura, Minas y Montes; 1918), — prácticamente la única publicación o resultado de la actividad de la ISC citada hasta $2005^{3}$ - . Por todo ello, nuestra percepción acerca del papel desempeñado por la ISC en el proceso de modernización de la Salud Pública española no le daba valor particular. Sin embargo, un trabajo realizado conjuntamente con Alfredo Menéndez-Navarro sobre el problema de la anquilostomiasis mostró pruebas de que la intervención del mencionado organismo fue más allá de lo que su (escasa o mala) fama permitía suponer ${ }^{4}$. En efecto, encontramos que la ISC resultó decisiva para poner en marcha la primera legislación específica de prevención de una enfermedad del trabajo en un entorno industrial concreto, el de la minería. Las medidas dispuestas en sendos decretos de 1912 y 1916 prefiguran en lo fundamental la legislación correctora que adoptó el gobierno de Primo de Rivera en 1926, tras el viaje de inspección que realizó Charles Bailey, enviado de la Fundación Rockefeller. En sí mismo, nos encontramos con un interesante ejemplo de «olvido» (¿interesado?) de antecedentes inmediatos, producto de una indagación epidemiológica y cuyo contenido era perfectamente homologable con

3 Pittaluga, G. (1922), Trabajos de la Comisión para el Saneamiento de Comarcas Palúdicas, Anuario Dir. Gen. Sanidad, 1921, p. 422; PitTAlugA, G. (1923), Enfermedades de los países cálidos y parasitología general, Madrid, Calpe, pp. 414 y 426; PASCUA, M. (1928), Algunas notas sobre el paludismo en España. En Memoria de la campaña contra el paludismo (1925-1927), Madrid, Ministerio de la Gobernación, pp. 442-520; PASCUA, M. (1930), Suplemento a las notas sobre el paludismo en España. En Memoria de la campaña contra el paludismo (1928-1929), Madrid, Ministerio de la Gobernación, pp. 411-416. La única otra publicación citada (memoria de 1912) en BArona, J.L., BernabeU-Mestre, J. y Perdiguero, E. (2005), Health problems and public policies in rural Spain, 1854-1936. En BARONA, J.L. y CHERry, S. (eds.), Health and Medicine in Rural Europe (1850-1945), Valencia, Seminari d'Estudis sobre la Ciència, pp. 63-82, p. 75.

4 Rodríguez-OcaÑA, E. y MenÉndeZ-NAVArRo, A. (2006a), Higiene contra la anemia de los mineros. La lucha contra la anquilostomiasis en España, 1897-1936, Asclepio, 58 (1), pp. 219-248. 
las normas más avanzadas de su época. Sin embargo, ni en 1926 ni con posterioridad nadie reclamó la recuperación de aquellos trabajos pioneros.

Esto condujo a que me replanteara el análisis de esta institución y que me decidiera a realizar una búsqueda sistemática de fuentes primarias, obviando, al menos provisionalmente, la imagen transmitida, y hacer caso así a la advertencia de Félix de Azúa, quien ha escrito que si bien la historia no suele repetirse, sí que lo hacen continuamente los historiadores ${ }^{5}$. Para ello me propuse la recuperación sistemática de todos los fondos pertenecientes a dicho organismo. Si bien el Archivo General de la Administración no se ha mostrado propicio hasta la fecha en cuanto a documentación, sí he encontrado numerosas informaciones de importancia en el Boletín de Agricultura técnica y económica, que se publicó mensualmente como órgano oficial de la Dirección general de Agricultura, Industria y Comercio desde 1909. Igualmente he intentado verificar, con éxito nulo, los fondos procedentes de los Consejos Provinciales de Fomento, con los que mantuvo relación administrativa la ISC, con la dificultad de su natural dispersión y aleatorio estado de conservación. En realidad los impresos encontrados de esta procedencia, salvo en un caso, no tenían relación con el tema de búsqueda. Igualmente he realizado el examen completo y sistemático de un número de revistas médicas de la época (Revista de Medicina y Cirugía Prácticas, Revista Iberoamericana de Ciencias Médicas, Gaceta Médica Catalana — todas, entre 1910 y 1918- y Medicina Ibera, 1917-18), considerando que El Siglo Médico ya había sido escrupulosamente revisado por Rico-Avello. Junto con las revistas, tuve la suerte de localizar en la Biblioteca del antiguo Hospital Provincial de Granada (Hospital San Juan de Dios) los Boletines que acompañaban a dichas revistas, donde, con formato y numeración independiente, se recogía la mayor parte de las informaciones de actualidad, habitualmente no conservados. Lo que sigue se sustenta en el análisis de lo encontrado en mi pesquisa.

\section{LA INSPECCIÓN DE SANIDAD DEL CAMPO: SU ORGANIZACIÓN Y FUNCIONES}

El 25 de noviembre de 1910, el Ministerio de Fomento regido entonces por Fermín Calbetón ${ }^{6}$ en un Consejo presidido por José Canalejas, promulgó

5 AzúA, F. DE (2000), Historia, El País, 5 de julio.

6 Fermín Calbetón Blanchón (San Sebastián, 1853-Madrid, 1919), abogado y catedrático de Hacienda, se inició en la política en Cuba y desde 1887 ejerció puestos de alta responsabilidad en la administración central española siempre en el ámbito del partido Liberal. 
un Real Decreto por el que se creaba, dentro de la Dirección General de Agricultura, un órgano para llevar a cabo «la acción del Estado en cuanto se refiere a la higiene y salubridad del suelo, subsuelo y aguas de las comarcas y terrenos rurales» ${ }^{7}$. Ello requería, a juicio del legislador, añadir competencias médicas a las propias, agronómicas, sin por ello cuestionar que la jerarquía de las cuestiones sanitarias correspondía de manera «omnímoda y exclusiva» al Ministerio de Gobernación. La justificación de motivos se amplió en la Memoria publicada al final del primer año de actividad del nuevo Servicio. Partía de constatar la quiebra de lo que Josep Bernabeu ha denominado el mito de la salud rural:

aquellas cualidades salutíferas de los campos son ilusorias, porque en ellos ni el suelo ni el subsuelo son sanos; el aire y el agua no son puros, ni los alimentos son siempre inofensivos ni las viviendas higiénicas ${ }^{8}$.

Y como quiera que el medio rural era el venero de la población, su saneamiento se postulaba por conveniencia general de la nación, en tanto que la atención a su bienestar garantizaría la fortaleza nacional. Al mismo tiempo, podrían evitarse las pérdidas económicas anejas a la morbimortalidad rural, en particular por enfermedades como las fiebres tifoideas y el paludismo, esto es las «hídricas y telúricas», algo de lo que daba cuenta, aunque con deficiencias, la estadística demográfica del Instituto Geográfico. En el preámbulo del RD se citaba que, en 1907, el total de fallecidos por causa de enfermedades hídricas y telúricas sumaba más de la cuarta parte del total de la mortalidad española, así como que se perdían al año 24 millones de días de trabajo por enfermedades intestinales. En la Memoria de 1912 se añadían al «empobrecimiento nacional» así producido fenómenos como la «despoblación de muchísimas regiones» y la depreciación del valor de la tierra9 ${ }^{9}$

Existía un ejemplo histórico cercano: la campaña de saneamiento a gran escala practicada por Estados Unidos en Cuba después de la guerra hispano-

\footnotetext{
7 RD 25 noviembre 1910, Gaceta del 26, pp. 459-461.

8 Sanidad del Campo (1912). En Parte de la Memoria del Director general de Agricultura, Minas y Montes D. Tesifonte Gallego García é Informe que el Inspector general de Sanidad del Campo D. A. Muñoz eleva como resultado de la inspección que ha practicado en las regiones de Castilla la Vieja, Leonesa, Galicia y Asturias, Extremadura, Andalucia y parte de Levante, Madrid, Ricardo F. de Rojas, pp. 4-8 (cita de p. 5); BERnABEU, J., State of health of the Catalan areas: the work of the Academia d'Higiene in the early 20th century. En BARONA Y CHERRY (eds.) (2005), p. 291.

9 Sanidad del Campo (1912), p. 6.
} 
norteamericana, y una amenaza pendiente: el miedo a la extensión de la epidemia de cólera aparecida en Italia en ese año, argumentos ambos que hacían oportuna la iniciativa gubernamental. El cólera se presentó, en efecto, en algunas localidades tarraconenses en 1911 y fue afrontado enérgicamente por el Instituto Nacional de Higiene y la sanidad oficial. El ejemplo norteamericano no parece haber servido más que de sostén retórico a la norma legislativa, pues nada en lo realizado por el nuevo organismo se aproximó a la obra dirigida por William Gorgas. En la Memoria de 1912 se insertaba la iniciativa española en una panorámica internacional donde figuraban el Servicio de Higiene del Departamento de Agricultura de los Estados Unidos y la Inspección de Sanidad rural belga, la legislación italiana sobre malaria y la figura de los inspectores de salubridad británicos, como ejemplos de acción gubernativa enfocada hacia el saneamiento agrícola y separada de los servicios sanitarios clásicos. Como en estos países, pues, convenía preparar obras de ingeniería «tomando en cuenta la higiene» ${ }^{10}$.

No hay duda de que el auténtico motor que propulsó la creación de este organismo fue la argumentación de corte poblacionista y economicista que es el nexo que integra la preocupación por la salud en el universo ideológico del desarrollo capitalista. Esa fue también la argamasa del pensamiento médicosocial que, en líneas generales, se desarrolla en toda Europa por estas fechas, movimiento del que no queda exenta España ${ }^{11}$.

La ISC se componía de una dirección central formada por un Inspector general (IG), residente en Madrid, y dieciséis Inspectores regionales (IIRR), asentados en las ciudades capitales de provincia dotadas de Granjas-Escuelas prácticas de Agricultura (que en algún caso, como el de Palma de Mallorca, se creó con posterioridad a la dotación de la ISC), todos ellos médicos, si bien debían contar con la asesoría, en cada caso, de ingenieros. En la reforma del Reglamento dispuesta en 1916 se incluyó la figura de los Inspectores Supernumerarios, adscritos a la Inspección General, preparados para sustituir interinamente a los IIRR que obtuvieran la excedencia ${ }^{12}$. También en 1916 se les imbricó más profundamente en el organigrama de Agricultura, ligándola a las Direcciones Hidráulicas y las Jefaturas de Obras Públicas y al disponer que los IIRR — convertidos en vocales na-

10 Sanidad del Campo (1912), pp. 8-12.

11 RodrígueZ-OcAÑA, E. (2007), Medicine as a Social Political Science: The Case of Spain c. 1920, Hygiea Internationalis, 7 (1), pp. 37-52.

12 Los Reglamentos que ordenaron la función de la ISC se dispusieron como sendos Reales Decretos en 18 octubre 1913 (Gaceta del 22, pp. 140-147) y 8 agosto 1916 (Gaceta del 11, pp. 309-317), respectivamente. 
tos de los Consejos provinciales de Fomento - trabajarían en las GranjasEscuela $\mathrm{u}$ otras dependencias de Fomento dotadas con laboratorio, «a las órdenes de los Directores o Jefes de servicio correspondientes» ${ }^{13}$ -

Las funciones de la nueva Inspección se definieron del siguiente modo (art. 3):

Esta Inspección estudiará, investigará, fiscalizará y propondrá al Ministro de Fomento las reformas y obras necesarias para evitar toda causa de insalubridad de los campos, de la propagación y diseminación de enfermedades endémicas o epidémicas al través de estos por sus vías fluviales, subterráneas y conducciones de aguas potables, o por las hortalizas y frutos regados con aguas impuras.

Es decir, se pensaba en un plan de obras públicas en el medio rural justificado por razones higiénicas. Las obras propuestas correrían, según los casos, a cargo de la propia Inspección - supuesto que no hemos encontrado corroborado en la práctica-, a cargo de los municipios, solos o ayudados por el Gobierno, o bien por cuenta de los propietarios. Estarían respaldadas por la enseñanza y popularización de las técnicas de saneamiento entre «los interesados y naturales de la comarca» (art. 4). Es interesante advertir que se hace mención expresa de esta misión propagandística entre la población en general, al servicio de la cual se pondrían «personal y elementos materiales», por primera vez entre las competencias de un organismo sanitario nacional. El capítulo X del Reglamento de 1913 (promulgado por Rafel Gasset como Ministro de Fomento) precisó que esta tarea se traduciría en clases regladas para los alumnos de las Granjas-Escuela y «a cuantas personas lo solicitaran» (art. 47), según programas aprobados previamente con antelación a cada año académico, y en la impartición de conferencias divulgativas en algunas de las poblaciones inspeccionadas, en todo caso procurando concederles un cariz práctico y de estímulo a la acción social.

Los cargos de la Inspección se ocuparían mediante concurso entre doctores (el IG) o licenciados en medicina (los IIRR) con experiencia profesional en el medio rural; mientras el primero debería poseer un puesto oficial ganado por oposición, cuyo desempeño sería compatible con el nuevo puesto, pertenecer o

13 Art. 98, reglamento de 8 agosto 1916. Sobre las Granjas-Escuela, ver FERNÁNDEZ DE LA RosA, G. (1913), Apuntes históricos sobre los progresos de la agricultura española en los cincuenta años últimos. IV, Boletín de Agricultura técnica y económica, 52 [abril], pp. 335345. Por RD 9 agosto 1917 (Gaceta del 10 y, rectificación, el 11) se convirtieron en centros de enseñanzas medias, perdiendo sus funciones experimentales, excepto la Central, incorporada a la Escuela Especial de Ingenieros Agrónomos. 
haber pertenecido al Consejo de Sanidad, y haber publicado, preferentemente con premio, sobre higiene y salubridad, a los IIRR se les exigía conocimiento práctico de análisis bacteriológico y químico de aguas y al menos un año de estudio en el extranjero. Se quería que los puestos se ocupasen inmediatamente, a fin de que la ISC se pusiera en marcha con el nuevo año, por lo que los respectivos concursos se convocaron en seguida ${ }^{14}$. Pero en ese plazo solo se concedió la Inspección General, que fue para Antonio Muñoz Sánchez, médico de número del Hospital de la Princesa, nombrado el 28 de diciembre. Para las plazas inspectoras se recibieron 280 solicitudes, número que llevó a ampliar el plazo y el número de vocales del Tribunal ${ }^{15}$. Los puestos se cubrieron de entre una lista con los 81 seleccionados con puntuación superior a 20, establecida por una subcomisión compuesta por los tres médicos consejeros de Sanidad que formaban parte del Tribunal, incluyendo al propio Antonio Muñoz en su calidad de IG. Los Inspectores Regionales se nombraron el 31 de marzo y tomaron posesión el 15 de mayo de 1911, con cierto retraso por la crisis ministerial sucedida en el ínterin ${ }^{16}$. La relación de nombramientos y destinos se publicó a primeros de julio junto al recordatorio de los preceptos sobre residencia y modo de relación con las autoridades por los IIRR ${ }^{17}$. La primera oficina central estaba formada por el IG y los agregados inspectores médicos Francisco Masip y Vicente Jimeno e ingenieros asesores Teodoro Moreno Suit, de montes, y Francisco Bilbao Sevilla, agrónomo. El Reglamento denominó los puestos de inspectores agregados a la Inspección Central como Inspector secretario e Inspector de servicios, con ese mismo orden de prelación en el escalafón y en la capacidad de sustituir las ausencias del Inspector Jefe. Con referencia a los IIRR, su lugar de residencia y la región correspondiente se indican en la Tabla 1.

TABLA 1. Relación de Regiones e Inspectores regionales de Sanidad del Campo

\begin{tabular}{|l|l|l|}
\hline REGIÓN & INSPECTOR & LUGAR DE TRABAJO \\
\hline $\begin{array}{l}\text { Región de Castilla la Nueva } \\
\text { (Madrid, Toledo, Cuenca y } \\
\text { Guadalajara) }\end{array}$ & Juan Veranés Estella & $\begin{array}{l}\text { Granja-Escuela práctica de agricul- } \\
\text { tura regional, La Moncloa, Madrid }\end{array}$ \\
\hline $\begin{array}{l}\text { Región de la Mancha } \\
\text { (Ciudad Real y Albacete) }\end{array}$ & Francisco Morayta & $\begin{array}{l}\text { Granja-Escuela práctica de agricul- } \\
\text { tura regional, Ciudad Real }\end{array}$ \\
\hline
\end{tabular}

14 Gaceta, 27 noviembre 1910, pp. 483-484.

15 RO 24 diciembre 1910, Gaceta del 25, p. 699.

16 Sanidad del Campo (1912), pp. 1-4.

17 RO 3 julio 1911, Gaceta del 5, pp. 58-59. 


\begin{tabular}{|l|l|l|}
\hline REGIÓN & INSPECTOR & LUGAR DE TRABAJO \\
\hline Región de Extremadura & Darío Cañizal Loscos & $\begin{array}{l}\text { Granja-Escuela práctica de agricul- } \\
\text { tura regional, Badajoz }\end{array}$ \\
\hline $\begin{array}{l}\text { Región de Castilla la Vieja } \\
\text { (Ávila, Segovia, Soria, } \\
\text { Burgos y Valladolid) }\end{array}$ & $\begin{array}{l}\text { Eduardo García del } \\
\text { Real18 }\end{array}$ & $\begin{array}{l}\text { Granja-Escuela práctica de agricul- } \\
\text { tura regional, Valladolid }\end{array}$ \\
\hline Región de Aragón y Rioja & Luis Cerezo Sainz & $\begin{array}{l}\text { Granja-Escuela práctica de agricul- } \\
\text { tura regional, Zaragoza }\end{array}$ \\
\hline $\begin{array}{l}\text { Región Leonesa } \\
\text { León, Zamora, Salamanca, } \\
\text { Santander y Palencia) }\end{array}$ & Arturo Bustamante & $\begin{array}{l}\text { Granja-Escuela práctica de agricul- } \\
\text { tura regional, Palencia }\end{array}$ \\
\hline Región de Asturias y Galicia & $\begin{array}{l}\text { Tomás Gil de San } \\
\text { Lorenzo }\end{array}$ & $\begin{array}{l}\text { Granja-Escuela práctica de agricul- } \\
\text { tura regional, La Coruña }\end{array}$ \\
\hline $\begin{array}{l}\text { Región de Navarra y Vas- } \\
\text { congadas }\end{array}$ & $\begin{array}{l}\text { Manuel Naranjo } \\
\text { Rute }\end{array}$ & $\begin{array}{l}\text { Granja-Escuela práctica de agricul- } \\
\text { tura regional, Pamplona }\end{array}$ \\
\hline Región de Cataluña & $\begin{array}{l}\text { José Suárez de Fi- } \\
\text { gueroa19 }\end{array}$ & $\begin{array}{l}\text { Granja-Escuela práctica de agricul- } \\
\text { tura regional, Barcelona }\end{array}$ \\
\hline $\begin{array}{l}\text { Región de Levante } \\
\text { (Valencia, Alicante, Caste- } \\
\text { llón y Murcia) }\end{array}$ & $\begin{array}{l}\text { Ildefonso González } \\
\text { Colmenar[es] }{ }^{20}\end{array}$ & $\begin{array}{l}\text { Granja-Escuela práctica de agricul- } \\
\text { tura regional, Burjasot, Valencia }\end{array}$ \\
\hline $\begin{array}{l}\text { Región de Andalucía oriental } \\
\text { (Granada, Jaén, Málaga y } \\
\text { Almería) }\end{array}$ & $\begin{array}{l}\text { Bonifacio de la } \\
\text { Cuadra }\end{array}$ & $\begin{array}{l}\text { Granja-Escuela práctica de agricul- } \\
\text { tura regional, Jaén }\end{array}$ \\
\hline $\begin{array}{l}\text { Región de Andalucía occi- } \\
\text { dental (Sevilla, Cádiz, Cór- } \\
\text { doba y Huelva) }\end{array}$ & Rodolfo D’Angelo & $\begin{array}{l}\text { Granja provincial de Alfonso XIII, } \\
\text { Sevilla }\end{array}$ \\
\hline Región de Baleares & Angel Butrón ${ }^{22}$ & $\begin{array}{l}\text { Granja escuela práctica de agricul- } \\
\text { tura regional, Palma de Mallorca }\end{array}$ \\
\hline Región de Canarias & $\begin{array}{l}\text { Granja escuela práctica de agricul- } \\
\text { tura regional, Sta. Cruz de Tenerife }\end{array}$ \\
\hline Falles-
\end{tabular}

Fuente: RO de 3 de Julio de 1911 (Gaceta del 5), pp. 58-59

18 García del Real es quien figura en la Gaceta, pero la única referencia inmediata posterior a este cargo que he localizado lo asigna a Julián Vara, Sanidad del Campo (1912), p. 53.

19 Fallecido a primeros de 1918.

20 Figura «Colmenar» en la Gaceta, pero firma como Colmenares sus publicaciones.

21 Fallecido en 1917, según la convocatoria de nueva provisión de su puesto (Gaceta 5 mayo 1917, p. 46). Desconozco si se llegó a efectuar el concurso.

22 Obtuvo la excedencia, según la convocatoria de nueva provisión (Gaceta, 6 febrero 1917, p. 302). Desconozco si se llegó a efectuar el concurso. La Granja-Escuela práctica de Agricultura de Palma de Mallorca se creó por RO 14 febrero 1912 (Gaceta del 19) y tomó su tiempo el instalarla.

23 Obtuvo muy pronto la excedencia, según la convocatoria de nueva provisión (Gaceta, 8 mayo 1914, p. 316). 


\section{ACTIVIDADES DE LA ISC}

Las funciones asignadas por el RD de creación de la ISC se concretaron muy poco después, a mediados del mes de julio de 1911, por recomendación de su Inspector General, en forma de labor minuciosa de información que debía acometerse antes de poner en pie un plan de reformas que comprendiera las obras hidráulicas, nueva legislación sobre cultivos, el abastecimiento y purificación de las aguas potables, etc., mientras que, simultáneamente, desarrollaría una intensa labor de educación sanitaria ${ }^{24}$. Con vistas a la tarea informativa se confeccionaron una serie de cuestionarios, cuyo texto reproducía el periódico oficial, para su compilación por los Inspectores en colaboración con los Gobernadores civiles, Ayuntamientos, y otras entidades interesadas. Las instituciones, en particular municipales, a través de sus respectivos servicios médicos y técnicos, debían suministrar los datos y materiales requeridos por aquellos. El Reglamento de la ISC, promulgado en octubre de 1913, deta1ló, sin ninguna contradicción con lo estipulado de antemano, los objetivos, contenidos y finalidad de los cuestionarios, regulación que se confirmó en el nuevo texto reglamentario de agosto de 1916, también promulgado por Gasset. La organización de la oficina central seguía «un sistema de fichas norteamericano», de manera que todas las respuestas se almacenaban dentro de un expediente identificado con el número del municipio correspondiente, previamente extractadas ${ }^{25}$. La documentación original no he conseguido localizarla y dudo de que se conserve.

La investigación fue dirigida hacia los aspectos considerados como más problemáticos de la salud rural, a saber: el paludismo, las aguas potables, la alimentación de los jornaleros, la fiebre de malta y la anquilostomiasis. Se prometía recoger también en el futuro datos sobre actividades agrícolas, ganaderas y culturales, sobre enfermedades profesionales y sobre la vivienda.

A la vez que se hacía público el detalle de las funciones de la ISC, una circular del Ministerio de la Gobernación, firmada por Canalejas, expresaba la alta consideración con que los Gobernadores civiles deberían considerar las cuestiones de salud pública para combatir con la mayor eficacia las enfermedades evitables, y les ordenaba vigilar que se cumplimentaran los cuestionarios remitidos por la ISC ${ }^{26}$. En particular, destacaba la urgencia de la informa-

24 RO 14 julio 1911, Gaceta del 17, pp. 209-231. La autoría de Muñoz se afirma en Sanidad del Campo (1912), pp. 6-7.

25 Sanidad del Campo (1912), p. 17.

26 RO Ministerio de la Gobernación 28 julio 1911, Gaceta del 30, p. 327. 
ción sobre aguas potables, en aquellos momentos en los que existía la amenaza del cólera.

Ahora bien, los cuestionarios eran realmente prolijos y debían completarse para cada Ayuntamiento y entidad de población menor de España, por lo que suponían una tarea absolutamente ingente $\mathrm{y}$, en muchos casos, un trabajo original de investigación local, pues no cabe duda de que, si no la mayoría, muchos de los datos eran desconocidos. Como prueba, baste citar las exigencias del cuestionario sobre alimentación. La muestra tipo llena ocho páginas del periódico oficial. Comienza con la identificación de la región, provincia, distrito, ayuntamiento y entidades menores, anotando, para cada lugar, número de habitantes y riqueza agrícola, número de agricultores y de jornaleros y precio medio del jornal. A continuación se preguntaba sobre alimentos vegetales (legumbres secas, legumbres verdes, tubérculos y raíces, hortalizas y verduras, legumbres frutos, setas, frutas y cereales, cada caso desglosado en sus componentes individuales), alimentos animales (carnes de matadero, animales de corral, animales de caza, pescados, moluscos y crustáceos, igualmente descompuestos en sus distintas especies) productos animales (como leche, quesos, manteca, sebo y huevos, en cada caso según naturaleza), conservas (vegetales y animales, desglosadas), condimentos y bebidas (divididas en fermentadas, destiladas y no alcohólicas, con detalle). Para todos y cada uno de estos elementos individualizadamente se debía anotar la producción anual, el consumo y el precio medio, separando en el primer caso las cantidades producidas según su procedencia (local, limítrofe, nacional y extranjera) y el consumo por día y por año, por habitante y por obrero. De las conservas se debían precisar los procedimientos de conservación empleados, no se sabe si en proporción o en números absolutos. A continuación se preguntaba sobre el régimen alimenticio, la ración y la preparación culinaria, el combustible y utensilios empleados en las cocinas. El régimen alimentario se desglosaba en vegetal, mixto y animal, y había que indicar el horario, cantidad y composición de las comidas, separadamente las del invierno y las del verano. La ración había que expresarla en número de calorías (formando los grupos de excesiva, suficiente e insuficiente) y descomponerla en hidratos de carbono, albuminoides y grasas. El siguiente epígrafe hacía referencia al trabajo agrícola, subdividido en débil, moderado, fatigoso, muy fatigoso, y a los reposos o descansos, con mención del número de calorías consumidas en cada caso, así como duración de la jornada (horarios) en invierno y en verano. Seguía un epígrafe sobre fraudes en alimentos y bebidas, desglosado por tipos y elementos alimenticios, que incluía la mención a los análisis bromatológicos realizados. A continuación se trataban las enfermedades relacionadas con la alimen- 
tación (intoxicaciones y contaminaciones diversas, por continente o por contenido, de los distintos tipos de alimentos, bebidas y productos ya desglosados con anterioridad, incluyendo una pregunta por alcoholismo bajos sus diversas formas clínicas) y terminando con las derivadas de nutrición insuficiente (anemia, linfatismo, escrófula, raquitismo, tuberculosis, etc.). Los dos últimos epígrafes hacen referencia a otros aspectos no tratados y a los «proyectos y reformas necesarias».

Como se puede observar a simple vista, la cantidad y minuciosidad de la información solicitada la convierte en un ejercicio muy exigente, de difícil compilación y no menos ímproba vigilancia y supervisión, a las que estaban obligados los IIRR. Las respuestas, por otra parte, estaban formateadas de manera grosera (raciones alimenticias «excesivas», «suficientes» o «insuficientes», por ejemplo) y en muchos casos no recogían la observación inmediata, esto es, muchas respuestas debían ser previamente elaboradas a partir de una pluralidad, no determinada, de observaciones empíricas, para referirse a un «tipo» o «modalidad habitual», (por ejemplo, el régimen alimenticio) fuese cual fuese su fundamento empírico (el cual, por otra parte, no constaba en ningún sitio: de ahí las críticas retrospectivas que dirigió Marcelino Pascua a algunos de los Inventarios de la ISC, en tanto que metodológicamente inadecuados desde un punto de vista estadístico). En algunos de los trabajos publicados, los Inspectores regionales hablan de sus fuentes. El inspector catalán recurrió a diversos médicos y autoridades no identificadas, así como a su experiencia personal para informar sobre enfermedades relacionadas con la alimentación y el trabajo agrícola ${ }^{27}$. El inspector canario, por su parte, se dirigió a «la Dirección de Granja Agrícola y Jefatura Agronómica de la provincia, Ingenieros jefes de Obras Públicas y Montes, Jefe provincial de Estadística, Arquitecto municipal, Ingenieros militares [...] Inspecciones provinciales de Sanidad y de Higiene Pecuaria, Subdelegados de Medicina y médicos anteriormente titulares, Cámaras de Comercio y de Agricultura [...] Administración de Hacienda, Administración de Puertos francos, Diputación provincial, comerciantes al por mayor y gran número de particulares $[\ldots] »$ para encontrar que «no pudieron contestar $[\ldots]$ por desconocimiento $[\ldots]$ o carencia de antecedentes» ${ }^{28}$. Con estas obligaciones, de hecho, la ISC competía con

27 SuÁrez de FigueroA, J. (1917a), Enfermedades determinadas por la alimentación en el obrero agrícola de la provincia de Barcelona durante el año 1916. Morbilidad, Gac. Med. Catal., 40 (2), pp. 365-367.

28 Selma, J. (1911), Generalidades sobre el Archipiélago Canario, en relación con la Sanidad del campo, Bol. Agric. Tec. Econ., pp. 929-946, p. 933. 
la Inspección General de Sanidad del Ministerio de la Gobernación, que venía persiguiendo infructuosamente los mismos objetivos informativos a través de las Juntas locales o los Inspectores provinciales de Sanidad ${ }^{29}$. Pero si entendemos esto como un desafío, no hay duda de que la ISC lo ganó por goleada, como se justifica a continuación.

En junio de 1912 (con Villanueva como Ministro de Fomento) como en enero de 1914 (bajo Javier Ugarte) y en enero de 1916 (también con Ugarte) se reiteraron las órdenes para no cejar en la tarea informativa, enfocando particularmente hacia el paludismo, en el primer momento, paludismo, aguas potables y alimentación en la segunda ocasión, y apuntando a este último elemento en $1916^{30}$. En todos los casos se insistía en la colaboración de los Gobernadores (de hecho, la circular de enero de 1916 iba dirigida a los mismos Gobernadores, directamente) y se glosaba la importancia de la salubridad rural en términos de riqueza nacional, además de ordenarse explícitamente la intervención personal de los IIRR en forma de visitas de inspección a todas las zonas palúdicas o como compiladores directos de la información en lugares donde fuera necesario, lo que era una manera indirecta de apuntar a la falta de colaboración o impotencia de cierto número de municipios, en cuantía que no podemos precisar, pero sin duda elevada.

La actividad local de los Inspectores podía ser, además, promovida por los vecinos, como fue el caso de Villarrín de Campos, provincia de Zamora, que reclamó el auxilio real ante una masiva prevalencia de palúdicos en su término, o por propietarios individuales, como el del presidente de la Colonia agrícola de San Pedro de Alcántara (Marbella, Málaga) y expresidente del Senado Joaquín Sánchez de Toca, que solicitó el consejo de Fomento para sanear los focos palúdicos responsables de mantener un $40 \%$ de obreros agrícolas enfermos. En el primer caso, la visita del Inspector regional se acompañó de una inspección ambiental, la toma de muestras de sangre y la impartición de una conferencia pública, y se siguió de un informe detallando los focos y los medios agrícolas (tipo de cultivos) convenientes para sanearlos ${ }^{31}$.

29 RO Ministerio de Gobernación, 31 de diciembre de 1910, disponiendo un cuestionario para la redacción de un informe sanitario del término municipal, Gaceta, 4 enero 1911, p. 58; RO Circular, Ministerio de Gobernación, 13 septiembre 1915, ordenando averiguar el número de enfermos de tracoma por provincia, Gaceta del 14, p. 722.

30 RR.OO. 29 mayo 1912 (Gaceta del 6 de junio, pp. 551-552) y 31 enero 1914 (Gaceta del 7 de febrero, p. 336).

31 InSPECCIÓn DE SANIDAD DEl CAMPo (1918), Avances de los inventarios de Paludismo y Aguas Potables. Datos remitidos por los Inspectores Regionales, Madrid, Ministerio de Fomento, Dirección General de Agricultura, Minas y Montes, p. 1. 
Aunque Muñoz Antuñano, en una memoria premiada por el Instituto de Ingenieros civiles de España en 1921, afirma que el inventario del paludismo se publicaba anualmente ${ }^{32}$, sólo hemos localizado los corrrespondientes a 1912, 1913, 1916 (resumen general) y 191833. El IR de Cataluña publicó por separado los datos de su zona ${ }^{34}$. La difusión de los mismos queda confirmada por su empleo por Hauser en la redacción del capítulo correspondiente de su Geografía médica de la Península Ibérica, aparecido en 1913, y que fueron calificados como «importantísimos trabajos» en una reseña al libro ${ }^{35}$; también aparecieron en los textos premiados en 1921 del concurso de la Asociación de Ingenieros sobre «el problema sanitario de España», así como fueron citados por García Faria y otros en sesiones de la Sociedad Española de Higiene para exigir el inicio de una campaña nacional contra el paludismo ${ }^{36}$. Algún efecto práctico debió alcanzarse, aunque no podamos evaluarlo por falta de fuentes, en algunas de las cerca de 600 estaciones de ferrocarril ubicadas en comarcas palúdicas, pues los IIRR tuvieron la obligación de velar porque las Compañías aplicaran medidas de protección antimosquito ${ }^{37}$.

Sobre aguas potables se publicaron avances en julio de 1915 y en 1916, además del informe final de $1918^{38}$. Información sobre el tema llegó a la oficina central desde el primer año, así como el Inspector General se cuidó de atender este extremo en su viaje de inspección celebrado entre noviembre y diciembre de 1911, pues la alerta era máxima como producto de la amenaza

32 Galiana, M. ${ }^{a}$ E. y Bernabeu-Mestre, J. (2006), El problema sanitario de España. Saneamiento y medio rural en los primeros decenios del siglo XX, Asclepio, 58 (2), pp. 139164, p. 154.

33 SuÁrez de FigueroA, J. (1917b), El paludismo en España. Cuadro estadístico [de 1913], Gac Med Catal, 964 (8 de septiembre), p. 142; Sanidad del Campo. Organización y servicios. (1917), Bol. Agric. Tec. Econ., 103 (julio), pp. 612-619, pp. 613-614; INSPECCIÓN DE SANIDAD DEL CAMPO (1918).

34 SuÁrez de FigueroA, J. (1917c), El paludismo en Cataluña. Cuadros estadísticos del paludismo en Cataluña durante los años 1912, 1913 y 1915, Gac. Med. Catal., 961 (24 de julio), p. 26.

35 Toledo de la Cueva, F. (1913), Bibliografía. La Geografía médica de la Península Ibérica por el doctor Ph. Hauser, Rev. Med. Cir. Pract., 1296 (28 diciembre), pp. 462-466.

36 García Faria, P. (1920), Lucha contra el paludismo. Discurso pronunciado en la Sociedad española de Higiene, Rev. Obras. Pub., 68, tomo I (n. $\left.{ }^{\circ} 2361\right)$, pp. 611-614. Se refiere a los comentarios de Francos y de Pittaluga.

37 Sanidad del Campo (1912), pp. 74-78.

38 Inspección de Sanidad de Campo. Avances del inventario de aguas potables (1915), Boletín suplemento al n. ${ }^{\circ}$ 1385, Rev. Med. Cir. Pract., 7 noviembre, pp. 75-76; Sanidad del Campo (1917), p. 617-618; INSPECCIÓN DE SANIDAD DEL CAMPO (1918). 
del cólera. «Estamos a la hora presente en una absoluta indefensión» contra ella, escribió en su informe, ante la generalizada contaminación de las aguas potables por materias fecales ${ }^{39}$. Los datos desprendidos de aquellas primeras aproximaciones (en el primer año llegaron más de 400 respuestas al cuestionario) produjeron una honda conmoción en el propio Inspector General, pues revelaban que «la extensión de nuestros males [...] era aún mucho mayor» de lo que se presumía ${ }^{40}$. Y sirvieron de argumento en el preámbulo del RD de 27 de marzo de 1914, que estipuló la contribución por el Estado a las obras de abastecimiento de agua para poblaciones ${ }^{41}$. Los avances del inventario de aguas hechos públicos en el otoño de $1915^{42}$ catalogaban alrededor de 12.000 fuentes y manantiales que suministraban agua para consumo en más de 7.300 municipios, con mención de su cantidad y calidad, origen, riesgos higiénicos en su afloración y tipo, estado de conservación y salubridad de las conducciones. Se incluyeron también los cálculos económicos requeridos por el cuestionario, resultando un coste total de sus consecuencias de 38.608 .040 ptas. Como el coste estimado de las obras de mejora era menos de tres veces superior, estas cifras se barajaban como un acicate para su rápida acometida.

El inventario de 1916 incrementó la información con datos de 900 municipios más, de manera que quedaban solamente 904 por informar del total de los 9.261 existentes. En datos totales se percibía una disminución de la prevalencia de las enfermedades asociadas, en morbilidad y mortalidad, que el Inspector General achacó sin dudarlo a la eficacia de la acción propagandística de su servicio de Sanidad rural. El problema principal seguía siendo el de las conducciones, pues de 13.825 abastecimientos explorados, sólo en el 9,9\% no se encontraba materia orgánica en suspensión, mientras que en el $31,4 \%$ ésta era abundante ${ }^{43}$.

El último acto de la ISC fue precisamente la aparición en 1918 de los Avances de los inventarios de Paludismo y Aguas Potables, saludada como prueba de su talento organizativo y laboriosidad ${ }^{44}$. Estos datos sirvieron para fomentar discusión a nivel local y no hay que descartar que también animaran

39 Sanidad del Campo (1912), pp. 78-85.

$40 \quad$ Sanidad del Campo (1912), pp. 66 y 69.

41 La parte dispositiva de este Real Decreto se publicó, sin preámbulo, el 28 de marzo, repitiéndose completo el día siguiente. RD 27 marzo de 1914, Gaceta del 28, p. 772 y del 29, pp. 780-781.

42 INSPECCIÓN DE SANIDAD DEL CAMPO (1915).

43 Sanidad del Campo (1917), pp. 617-618.

44 El paludismo y la Inspección de Sanidad del Campo (1918), Boletín supl. n. ${ }^{o} 1532$ Rev. Med. Cir. Pract., 28 noviembre, pp. 122-123. 
ciertas acciones de mejora por parte de algunos ayuntamientos. Colmenares publicó en una revista valenciana sobre «El problema del agua potable», en $1916^{45}$ y Suárez de Figueroa también hizo por divulgar algunos datos en Cataluña ${ }^{46}$, donde se dio la circunstancia de que las obligaciones de la ISC se convirtieron en ocupaciones de una institución rival. En efecto, se debe a Miguel Trallero, Inspector provincial de Sanidad de Barcelona, la confección de un pormenorizado estudio de las aguas de la provincia, incluyendo su análisis bacteriológico, que fue dando a conocer entre 1915 y 1916, por el orden alfabético comarcal, a través del periódico de Rodríguez Méndez ${ }^{47}$.

En el orden cuantitativo, el tercer elemento de importancia en la actividad de la ISC fue el dedicado a la información sobre alimentación. A comienzos de 1914 en la oficina central constaban los datos «de la mitad o más del total de municipios españoles $\rangle^{48}$. Desgraciadamente, desconocemos que ese material haya sido utilizado y es más que probable su destrucción. Uno de los primeros informes regionales, firmado por José Selma, se refirió de manera extensa a este asunto en la región canaria ${ }^{49}$; posteriormente se dio a conocer otro, procedente de Valencia, a cargo de Ildefonso García Colmenare ${ }^{50} \mathrm{y}$, por último, Suárez de Figueroa dio noticia acerca de enfermedades relacionadas con la alimentación entre los obreros agrícolas de la provincia de Barcelona ${ }^{51}$. Además, en 1915 se publicaron unos «Datos técnicos preliminares» para normalizar la recogida de informaciones regionales, con un interesante contenido divulgador sobre composición elemental de los alimentos, calorías y raciones alimenticias ${ }^{52}$, y se complementó al año siguiente con otro folleto de

45 En Policlínica. Revista mensual de Medicina, Cirugía y Especialidades. Citado entre las «Fuentes impresas» de BARONA, J.L. (2002), Salud, enfermedad y muerte. La sociedad valenciana entre 1833 y 1939, Valencia, Institució Alfons el Magnànim.

46 Las aguas potables en Cataluña. Avance de datos estadísticos de las aguas potables del partido judicial de Viella (provincia de Lérida) (1917), Gac. Med. Catal., 953 (15 de marzo), p. 178.

47 Trallero, M. (1915), Las aguas en la provincia de Barcelona. Arenys de Mar, Gac. Med. Catal., 1915 (2), pp. 322-325, Badalona: pp. 365-373, Berga: 1916/1, pp. 17-22, Calella: pp. 62-65, Manresa: pp. 99-102, Sitges, pp. 139-141.

48 Alimentación del obrero del campo. Datos técnicos preliminares (1915), Bol. Agric. Tec. Econ., pp. 141-151, p. 141.

49 Selma (1911).

50 Colmenares, I.G. (1914), Apuntes para un estudio de la ración alimenticia normal del obrero del campo, Bol. Agric. Tec. Econ., 69 [septiembre], pp. 833-838.

51 SuÁreZ DE FigueroA (1917a).

52 Alimentación del obrero del campo (1915). 
libre distribución publicado simultáneamente por la Dirección General de Agricultura, que reproducía los datos de la región valenciana ${ }^{53}$. Es preciso insertar estas preocupaciones en las generales de la sociedad española sobre la carestía de alimentos durante la época de la Guerra Mundial, problemas que eclosionaron en 1916 (Ley de subsistencias) y obligaron a la creación de una Comisaría General de Abastecimientos en 1917 que alcanzó efímero rango ministerial entre 1918 y 1920. De los dos informes regionales hechos públicos, el referido a Canarias había concluido que la alimentación habitual de los trabajadores del campo era suficiente para sus necesidades laborales e, incluso, su componente fundamental, el gofio (harina de cereales tostados, amasada con agua), resultaba «de primera calidad». Teniendo en cuenta las pesadas realizadas por el IR en distintas comarcas, la alimentación media de los obreros agrícolas se componía de seis kg. de gofio, tres de patatas, kilo y medio de pescado seco y 300 gr. de queso para los seis días que trabajaba seguidos fuera de su casa cada semana, lo que suponía 4.600 calorías diarias ${ }^{54}$. El informe firmado a 20 de agosto de 1914 en Valencia, por el contrario, terminaba afirmando que la ración alimenticia familiar media, de 7.567 calorías para dos adultos y dos niños, aun cuando se podía considerar fisiológica por su composición proporcional de hidratos de carbono, grasas y albúminas, resultaba insuficiente para personas en situación de reposo y claramente deficitaria para el trabajo o situaciones como el embarazo y la lactancia. García Colmenares seguía más fielmente el estadillo de preguntas del Cuestionario oficial y daba los datos etnográficos (tiempo de trabajo según temporadas, jornales, horario y composición de las comidas, etc.). Según sus cálculos, una familia media empleaba 1,5 ptas. diarias en su ración de alimentos, en una región donde el jornal de los varones oscilaba entre las 2,50 ptas. en invierno y las 4,50 en verano, el de las mujeres, entre 1 y 2 ptas. y el de los niños, entre 0,5 y 2. Los alimentos más comunes eran el arroz y el pescado seco y salado, mientras que verduras y frutas eran más habituales de las zonas de litoral y siempre de los desechos de los mercados interior y de exportación.

Una actividad más puntual, pero grandemente efectiva, fue la desarrollada en torno a la anquilostomiasis de las minas de Linares, que no voy a detallar al haber sido recientemente analizada ${ }^{55}$.

53 Ministerio de Fomento. Dir. Gral. De Agricultura, Minas y Montes (1916), Alimentación del obrero del campo: apuntes para su estudio, Madrid, Imprenta Ricardo F. de Rojas.

54 SELMA (1911), pp. 942-944.

55 RodríGueZ-OcAÑA y MENÉndeZ-NAVARro (2006a) y (2006b), La tardía intervención 
Las labores informativas topaban con una barrera administrativa: la restricción de los desplazamientos fuera del lugar de trabajo asignado. Los Reglamentos de 1913 y 1916 explicitaban que la IG asignaría el número de días y la época para realizar esas tareas, además de que podría asignar visitas específicas en cualquier momento. Todas ellas recibirían la correspondiente asignación de dietas. Esta norma restringía gravemente la iniciativa de los inspectores y se oponía de hecho a la ambiciosa descripción de tareas a cumplir, que exigía «inspeccionar, fiscalizar y estudiar, siempre que puedan, sobre el terreno los asuntos que afecten al servicio». En la práctica, vendría a significar que no se desplazaban, salvo por orden expresa de la superioridad, como en los casos señalados antes de intervención real (Villarrín de Campos) o del Ministerio de Fomento (Linares, San Pedro del Alcántara). Este mismo obstáculo fue señalado por Charles Bailey en su viaje por España al discutir la escasa efectividad de unos Inspectores provinciales de Sanidad limitados a ocupar un despacho en la capital ${ }^{56}$.

De todos modos, entre las actividades de la ISC publicadas, destaca la extrema laboriosidad de su IR para Cataluña, José Suárez de Figueroa y Cazeaux. Suárez no se limitó a recoger las noticias sobre paludismo, aguas o alimentación, que lo hizo y ganó incluso un Diploma de Honor para la ISC en el II Congreso de Médicos en Lengua Catalana ${ }^{57}$, sino que escrutó el ambiente laboral que le era próximo, en concreto el cultivo del arroz ${ }^{58}$ y la obtención

higiénica en el medio rural español: el caso de la lucha contra la anquilostomiasis, 1910-1960, La Mutua, 16 (2 época), 71-86.

56 RodrígueZ-OCAÑA, E. (2001), El Informe sobre la sanidad española (1926) de Charles A. Bailey, enviado de la Fundación Rockefeller, Cronos, 4 (1-2), pp. 63-79.

57 SuÁrez de FigueroA (1917b y c); SuÁrez de FigueroA, J. (1917d), Contribuciò a l'estudi del paludisme en la provincia de Girona. En II Congres Metges Llengua Catalana. Actes, Barcelona, pp. 211-218; SuÁrez DE FigueroA, J. (1917e), Las aguas potables en Cataluña. Avance de datos estadísticos de las aguas potables del partido judicial de Viella (provincia de Lérida), Gac. Med. Catal., 1, p. 178; SuÁrez De FigueroA, J. (1917f), Datos para la geografía médica de Cataluña. El paludismo en S. Vicente de Calders, Gac. Med. Catal., 1, pp. 332-335.

58 SuÁrez de FigueroA, J. (1915a), Las neuritis de los obreros de los arrozales, Rev. Med. Cir. Pract., CVIII, 1372, pp. 135-138; SuÁReZ De FigueroA, J. (1915b), Descripción clínica de las neuritis de los obreros de los arrozales, Rev. Med. Cir. Pract., 1373, pp. 169172; SuÁreZ DE FigueroA, J. (1915c), Algunos datos para el conocimiento de la geografía médica de la «neuritis de los obreros de los arrozales» en Cataluña, Rev. Med. Cir. Pract., 1379, pp. 412-413; SuÁreZ DE FigueroA, J. (1915d), Los pequeños síntomas de las neuritis de los obreros de los arrozales, Rev. Med. Cir. Pract., 1382, pp. 49-50; SuÁReZ DE FigueroA, J. (1915e), Distintos trabajos en el cultivo del arroz y su relación con las neuritis. Gráficos de 
del cáñamo ${ }^{59}$, si bien antes de pertenecer a la ISC ya había prestado atención puntual a los efectos morbosos del trabajo ${ }^{60}$. Existe testimonio impreso, igualmente, de su cumplimiento del deber de propagandista sanitario ${ }^{61}$. Leyó su tesis de doctorado sobre La neurastenia y los trabajos mentales en noviembre de 1908, tras lo que se identificó como «especialista en enfermedades nerviosas y mentales»; figuró como alumno honoris causa en el Instituto Rubio, en el curso 1910 a $1911^{62}$, cuando aparece interviniendo en sesiones tanto del Ateneo de Madrid como de la Academia Médico-Quirúrgica hablando sobre el paludismo ${ }^{63}$. Allí indicó que había pasado dos años (previsiblemente, 1908-1910) en la provincia de Tarragona, seguramente en la comarca del Bajo Ebro pues tiene publicada una topografía médica de Tortosa $(1913)^{64}$. En la citada Academia, Pittaluga le recomendó que investigara la población de vectores, apuntando, sin decirlo directamente, hacia cierta afirmación peregrina dejada caer por Suárez. En efecto, la explicación que este ofreció de la exacerbación palúdica vivida en las tierras del Delta mencionaba la construcción de un nuevo canal de riego y el consiguiente movimiento de

las neuritis, Rev. Med. Cir. Pract., 1390, pp. 370-372. Varias de estas publicaciones se recogieron en un folleto, según da cuenta una reseña: Bibliografía. José Suárez de Figueroa. Las neuritis de los obreros de los arrozales, Madrid, 1915, Rev. Ibero-Amer. Cien. Med., 1915 (1), pp. 278-279. En el trabajo titulado «Los pequeños síntomas...», indica que en 1912 presentó a la Academia Médico-Municipal de Barcelona una memoria sobre «Hiperhidrosis en los obreros de los arrozales». Todavía publicó en 1916, Las neuritis de los arrozales en las mujeres, Gac. Med. Catal., 39 (1), pp. 361-363.

59 SuÁreZ DE FigueroA, J. (1916), Alteraciones nerviosas de los obreros trabajadores del cáñamo, Rev. Med. Cir. Pract., CXIII, 1438, pp. 361-363.

60 SuÁrez de FigueroA, J. (1911), Un caso de trastornos auriculares por accidente de trabajo, Rev. Med. Cir. Pract., XCL, 1173, pp. 327-328 (se identifica como Doctor en Medicina, con domicilio en Madrid).

61 SuÁRez de Figueroa y Cazeaux, J. (1917), Conferencia dada en el Instituto Catalán de San Isidro sobre algunos conocimientos biológicos interesantes a los agricultores: para evitar las enfermedades en el hombre, en los animales de labor y en las aves de corral, Barcelona, Consejo Provincial de Fomento.

62 Boletín adjunto a. Rev. Ibero-Am. Cien. Med., diciembre 1916, 20.

63 SuÁrez de FigueroA, J. (1911a), [en el Ateneo de Madrid, 31 de marzo] El paludismo en España, Rev. Ibero-Amer. Cien. Med., 1 (26), pp. 168-178; (1911b), [en la Academia Médico-Quirúrgica Española, sesión del 24 de abril de 1911] El paludismo en España, Rev. Med. Cir. Pract., XCII, 1181, pp. 192-194.

64 SuÁrez de Figueroa y Cazeaux, J. (1913), Estudio higiénico y médico del partido judicial de Tortosa con un resumen de las aguas potables de Falset y Gandesa, Barcelona, Imp. de Pedro Ortega. 
tierras como favorecedora del parasitismo, como resultado del contacto entre el agua y restos vegetales, en la más rancia tradición miasmática. El consejo no cayó en saco roto y, en el verano de 1917, Suárez publicó el resultado de sus investigaciones al respecto ${ }^{65}$. Dio por buenas las investigaciones de Pittaluga de 1902 sobre la existencia de anófeles y él localizó otra especie, estegomia fasciata (nombre anterior del Aedes aegypti), vector de la fiebre amarilla, en distintas localidades catalanas, que mostró en sendos mapas, así como se dedicó a localizar los lugares de reproducción de los mosquitos (pozos, arrozales, balsas del cáñamo, balsas de pesca) y analizar procedimientos para obstaculizarla, básicamente mediante medidas que evitaran el estancamiento del agua. En 1915 actuaba como secretario del Comité del Claustro de Doctores de la Universidad de Barcelona ${ }^{66}$ y era médico de la Asociación de la Prensa de la misma ciudad ${ }^{67}$. Falleció por causa de la gripe a primeros de $1918^{68}$.

Si bien la actividad de Suárez de Figueroa ha de considerarse como excepcional, es posible, no obstante, que una revisión sistemática de publicaciones locales y regionales nos revelen un mayor grado de cumplimiento de las tareas teóricas de la ISC del que se le ha adjudicado tradicionalmente.

\section{LA INSPECCIÓN DE SANIDAD DEL CAMPO: EL CONTEXTO POLÍTICO}

La creación de la ISC ha de entenderse como parte de la llamada política de «regeneración hidráulica» que, como uno de los efectos más longevos del movimiento regeneracionista, sustentó los planes de modernización en el sector agrario que se fueron haciendo realidad paulatina a lo largo del siglo bajo los distintos regímenes políticos. Como tal estuvo ligado a la figura de Rafael Gasset Chinchilla (1866-1927) ${ }^{69}$, el Ministro firmante de los Reglamentos de

65 SuÁrez de FigueroA, J. (1917g), Causas y medios que influyen en la biología del mosquito, Rev. Med. Cir. Pract., CXVI, 1470, pp. 201-211.

66 José Suárez de Figueroa recibe una placa por suscripción..., Bol. Rev. Med. Cir. Pract., 7 de mayo de 1915, pp. 14-15.

67 Así se identifica en SuÁrez de FigueroA, J. (1917h), El temblor de la palabra, de los párpados y de las manos en los degenerados onanistas, Rev. Med. Cir. Pract., CXVII, 1483, pp. 250-252.

68 Noticia y lamento de su muerte en InSPECCIÓn DE SANIDAD DEL CAMPo (1918), p. 1; Bol. Rev. Med. Cir. Pract., 1918; supl. n. ${ }^{\circ}$ 1494, 73 y Gac. Med. Catal., 1 (1918); (n. ${ }^{\circ}$ 974, 31 de enero), 41.

69 Periodista, director de El Imparcial, diputado inicialmente conservador, y, tras la muerte de Fernández Villaverde en 1905, liberal. Fue reiteradamente Ministro de Agricultura 
la ISC y de varias de las disposiciones decisivas en su desempeño, y a otras figuras del Partido Liberal, como José Canalejas, Fermín Calbetón o el conde de Romanones, así como, en menor medida, a conservadores como Javier Ugarte y Eduardo Dato, proclives a la política hidráulica. La fecha de su puesta en marcha coincidió, no por casualidad, con la de la existencia de una amenaza de cólera, característica enfermedad ligada al agua y, finalmente, su desaparición fue obra de un gobierno presidido por Antonio Maura, el cual se distinguió siempre por su hostilidad hacia la línea Gasset ${ }^{70}$.

A diferencia de lo postulado por Carlos Rico-Avello en su Historia de la Sanidad española (1969), su creación no puede verse como un trastorno mental transitorio del gobierno de Alfonso XIII; antes bien, la vinculación entre las competencias de Fomento (recordemos: comercio, industria y agricultura) y las de Sanidad fue una decisión de gabinete, que obedecía, a mi parecer, a tres factores: la relevancia ganada por los aspectos de sanidad ambiental en el contexto de la ciencia bacteriológica, donde las enfermedades infecciosas se veían como 《enfermedades evitables» ${ }^{71}$; la (relativa) prioridad política alcanzada por la modernización agrícola (donde se iniciaron las campañas organizadas contra males colectivos, específicamente las plagas de langosta ${ }^{72}$ y se organizó la sanidad veterinaria); y la madurez alcanzada por la ingeniería civil en España. La sanidad veterinaria había comenzado en 1899 como responsabilidad de Gobernación, si bien un gobierno Maura la trasladó a Fomento en 1907-1908, donde se organizó la Inspección de Higiene y sanidad pe-

o de Fomento, y el máximo responsable del diseño de una política de obras públicas (riegos, carreteras, ferrocarriles) como palanca para la modernización de España, apenas desarrollada en la práctica por los obstáculos que se le enfrentaron, ínsitos en el sistema de poder de la Restauración. Véase Villanueva Larraya, G. (1987), Rafael Gasset: La política hidráulica en la acción del gobierno, Rev. Fac. Geogr. Hist., 1, pp. 439-459, accesible en http://espacio.uned.es/fez/eserv.php?pid=bibliuned:ETFSerie5-60F851A6-0FF5-8301-2A86-

F127F7C83E8D\&dsID=PDF (consultado el 31 de agosto de 2008); SÁnCHEZ ILLÁn, J.C. (1997), Rafael Gasset y la política hidráulica de la Restauración, 1900-1923, Rev. Hist. Econom., 15 (2), pp. 319-362, accesible en http://e-archivo.uc3m.es/dspace/handle/10016/2039 (consultado el 31 de agosto de 2008).

70 VARela Ortega, J. y DARdÉ Morales, C. (2000), El movimiento regeneracionista y la crítica del sistema político de la Restauración. En EsPADAS BURGOS, M. (coord.), La Época de la Restauración (1875-1902). Estado, política e islas de Ultramar, [Historia de España de R. Menéndez Pidal, Madrid, Espasa Calpe, XXXVI-1, pp. 537-553.

71 Porras Gallo, M.'I. (1994), La lucha contra las enfermedades 'evitables' en España y la pandemia de gripe de 1918-19, Dynamis, 14, pp. 159-183.

72 Buj BuJ, A. (1996), El Estado y el control de plagas agrícolas. La lucha contra la langosta en la España contemporánea, Madrid, Ministerio de Agricultura, Pesca y Alimentación. 
cuarias y se promulgó una ley de Epizootias en diciembre de $1914^{73}$. Hubo también intervención desde Fomento en cuestiones relativas a la higiene de los pasajeros en buques y trenes ${ }^{74}$.

Por otra parte, a primeros de 1910, el Ministerio de la Gobernación, a solicitud de la Asociación de Ingenieros de caminos, canales y puertos, decidió aplicar una lectura de la Instrucción General de Sanidad de 1904 que convertía en vocales natos de las Juntas provinciales de Sanidad a los Ingenieros Jefes de Obras Públicas (cargo del Ministerio de Fomento) ${ }^{75}$. Y en 1911, se ordenaba desde Gobernación a los Gobernadores civiles el colaborar con la ISC, al igual que en 1908 se les había ordenado con los Inspectores de Sanidad pecuaria ${ }^{76}$.

La primitiva descripción de funciones de la nueva Inspección, la contenida en el RD fundacional, parece dibujar la base médica de un plan de obras públicas en el medio rural. Recordemos que uno de los elementos regeneracionistas de la línea política representada por Gasset, con plena complicidad de los Colegios de Ingenieros, fue la pretensión de establecer planes de obras públicas (pantanos, canales, carreteras, ferrocarriles secundarios) a partir de estudios técnicos y no por la influencia parlamentaria de uno u otro diputado como venía siendo el caso. La aparición de la ISC parece indicar la apuesta por añadir la racionalidad salubrista a estas tareas, como complemento tentativo de los Planes nacionales de obras hidráulicas y el tímido inicio de la colonización agraria. La concreción funcional del nuevo organismo, volcada hacia el acopio de informaciones detalladas sobre aspectos problemáticos de la salud rural, participaba igualmente de una tradición liberal, la de la información social como preámbulo y, las más de las veces, sustitutivo de cualquier otra intervención gubernativa sobre las condiciones de vida y de trabajo

73 RO (M. ${ }^{\circ}$ de la Gobernación) creando en cada provincia una plaza de Inspector Veterinario de salubridad y otra de Subinspector, Gaceta, 02/02/1899, p. 399; RD sobre organización de los servicios de Agricultura y Ganadería (M. ${ }^{\circ}$ Fomento), 25 octubre 1907; Gaceta del 31, pp. 392-404; RO (M. ${ }^{\circ}$ Fomento) nombrando Inspectores provinciales de Higiene pecuaria, Gaceta, 16/02/1908, p. 668; Dirección general de Agricultura, Industria y Comercio. -Personal-. Concurso para proveer la plaza de Inspector Jefe del servicio de Higiene pecuaria, Gaceta, 31/12/1908, p. 1303; Ley de Epizootias, Gaceta 19/12/1914, pp. 835-837 y 18/1/1915, pp. 157-159.

74 RR.OO. Gaceta, 1/12/1906, p. 841; 14/07/1911, p. 187; 30/08/1911, pp. 567-569; 18/11/1911, p. 369; 20/08/1912, p. 399; 19/09/1912, p. 671; 4/10/1912, p. 39; 19/09/1913, p. 672.

75 RO 8 enero 1910, Gaceta del 11, p. 58.

76 Inspección general de Sanidad exterior. Disponiendo que por los Gobiernos de provincia se facilite a los Inspectores de Higiene pecuaria los datos de epizootias y estadísticas de ganados, Gaceta, 17/05/1908, p. 827. 
de la población. El periodo de la Restauración significó el florecimiento de las indagaciones sobre la vida social, con especial intensidad a partir de la llegada al poder de los liberales en 1881, como señaló hace algún tiempo Guereña 77 — baste recordar la actividad de la Comisión (luego Instituto) de Reformas Sociales, que no dejó de incluir la vida campesina entre sus objetivos (procesos informativos en 1900, 1902, 1903, 1906, 1919, 1920 y $1923)^{78}$ - . En este contexto, la Higiene Pública mostró su reconocida «dimensión política» también en sus métodos, puestos al servicio de situaciones concretas y no menos necesitadas de reforma de la vida nacional como eran los problemas de salubridad, tal como ejemplificaron las contribuciones de un Felipe Hauser, por ejemplo ${ }^{79}$. Desde esta perspectiva el diseño de la ISC era perfectamente congruente con los supuestos políticos liberales de realizar estudios antes que producir una legislación rupturista y con los supuestos científicos clásicos de la Salud pública, que combinó con el recurso al laboratorio, la preocupación por la divulgación sanitaria y la evaluación económica de las medidas de impacto ambiental.

\section{CONCLUSIÓN}

La historiografía no ha sido amable con esta institución, que se ha despachado sumariamente en general, siguiendo el juicio retrospectivo de Carlos Rico-Avello, como una competencia desleal al monopolio sanitario (entiéndase, del Cuerpo de Sanidad Nacional, el vinculado con Gobernación y al que dicho autor pertenecía $)^{80}$. En efecto, la organización separada de la sanidad rural, sin vinculación alguna con la administración general sanitaria, ni si-

77 GuereÑA, J.-L. (1989), Fuentes para la historia de la sociabilidad en España, Estudios de Historia Social, 50-51, pp. 273-305.

78 García Delgado, J.L., SÁnchez Jiménez, J. y Tuñón de LARA, M. (1984), Los comienzos del siglo XX. La población, la economía, la sociedad. En Historia de España fundada por R. Menéndez Pidal, Madrid, Espasa Calpe, XXXVII, p. 308.

79 RodríGUEZ-OCAÑA, E. (2005), La encuesta sanitaria como contribución original de Philip Hauser a la Salud Pública española. En Salud Pública en España: Ciencia, profesión, politica, siglos XVIII-XX, Granada, Universidad de Granada, pp. 215-234.

80 Este autor emplea términos rudamente descalificatorios: su creación fue «decisión realmente vejatoria» (p. 55), su organización independiente era «escarnio» (p. 56), su actividad fue «desconcertante» (p. 177), «interfiere» (p. 56), «francamente agobiante» (p. 179), todo desde la perspectiva de lo que él mismo denomina «Sanidad oficial»; RICO-AVELLO (1969). 
quiera en sus exigencias formativas, puede entenderse como un obstáculo para la consolidación profesional. Sin embargo, la escasa entidad de la formación sanitaria reglada dependiente del Instituto Nacional de Sanidad en estos años relativiza este obstáculo en la perspectiva histórica.

En términos de efectividad, el Ministerio de Fomento se mostró mucho más activo y resolutivo que la Inspección General de Sanidad de Gobernación. Así, puso en pie una Ley de profilaxis de enfermedades animales en 1914, mientras que las intervenciones defensivas sobre la salud humana no consiguieron rango superior al de Real Decreto (como los de Instrucción General de Sanidad, 1904; Bases para la profilaxis de las enfermedades venéreosifilíticas, 1918; Declaración de enfermedades infecciosas, 1919, etc.). La legislación protectora contra la anquilostomiasis en las minas (1912 y 1916) de Fomento fue absolutamente pionera en cuanto a la intervención en el medio laboral. Las descripciones cuantitativas del estado del servicio de abastecimiento de aguas, la prevalencia del paludismo y la alimentación campesina (esta última, no recogida en una publicación general) sirvieron de puntos de apoyo para medidas de fortalecimiento de las infraestructuras municipales (cofinanciación de proyectos de abastecimiento de aguas) y, eventualmente, como reclamo para justificar la implantación de la lucha antipalúdica a nivel estatal, iniciada en 1920. A la vez, la propia existencia de la Inspección sanitaria rural y su diseño dentro de las políticas de regeneración hidraúlica elaboradas por Rafael Gasset nos remite a la manifestación de una conciencia pública de modernización agrícola que incluía como objetivo la defensa de la salud de la mayoría de la población española. Que dicha conciencia fue limitada y que otros problemas de Estado alcanzaron prioridad sobre este asunto no tiene discusión, pero el fracaso o la falta de realización de las tareas desprendidas de dichas informaciones es achacable al propio régimen político oligárquico.

Ahora bien, el problema no planteado hasta la fecha es el porqué de su olvido radical. El gobierno Maura de 1918 no unificó esta Inspección del Campo con las restantes sanitarias, contra lo que afirma Rico-Avello ${ }^{81}$, sino que la clausuró, en medio de la grave epidemia gripal que soliviantó a las fuerzas vivas de la medicina española en busca de mejoras. El cierre total desaprovechó cuantas ventajas podrían haberse derivado de su experiencia y de su relación con parcelas tan notables en materia de sanidad ambiental como la salud veterinaria y las obras públicas, así como su preocupación por la alimentación, algo que no se recuperaría para la Sanidad hasta la República. Proba-

81 Rico-Avello (1969), p. 177. 
blemente, el enfoque «telúrico» que la sustentó se oponía al microbiano y parasitológico que era dominante en el terreno científico (Pittaluga), a lo que hay que sumar las resistencias a aceptar una fuente de autoridad distinta de la asentada en la Sanidad de Gobernación y sus aledaños (los Martín Salazar, Pulido, Cortezo, etc.). Su abrupto cierre solo dejó recuerdo de un esquema burocrático frustrado, por carecer de los medios y, seguramente también, de una dirección suficientemente experta en Salud Pública.

Fecha de recepción: 19 de enero de 2009

Fecha de aceptación: 9 de mayo de 2009 